\title{
ARTIGO
}

COI https://doi.org/10.22481/praxisedu.v15i34.5460

\section{O ENSINO MÉDIO NO BRASIL: AUSÊNCIAS SILENCIADAS}

\author{
HIGH SCHOOL IN BRAZIL: ABSENCES SILENCED
}

ENSEÑANZA SECUNDARIA EN BRASIL: AUSENCIAS SILENCIADAS

\section{Gilvan Luiz Machado Costa}

Universidade do Sul de Santa Catarina - Brasil

\begin{abstract}
Resumo: $\mathrm{O}$ artigo tem como objetivo compreender os limites e as perspectivas à universalização do acesso e à valorização do professor no Ensino Médio. A discussão foi realizada com base em indicadores educacionais arrolados à qualidade social, com destaque para Taxa Líquida de Matrícula, Adequação da Formação e o Esforço Docente. A análise explicita um contexto distante do proposto nas metas 3, 15, 17 e 18 do Plano Nacional de Educação (2014-2024) e evidencia desafios relacionados à universalização do acesso, à formação inicial e às condições de trabalho do professor do Ensino Médio. Sugere que o problema da qualidade social do Ensino Médio não se resolverá com a flexibilização curricular proposta na Lei 13.415/2017. A qualidade social reivindica a universalização do acesso, mormente aos jovens de 15 a 17 anos, e a transformação da docência em uma profissão socialmente atraente. Dimensões subestimadas nas discussões do tempo presente pelos defensores da reforma.
\end{abstract}

Palavras-chave: Condições de trabalho. Formação inicial. Universalização.

\begin{abstract}
The article has as aim to understand the limits and perspectives to the universalization of the access and the appreciation to the teacher in the High School. The discussion was carried out based on educational indicators regarding to the social quality, highlighting the Liquid Frequency Rate, Training Adequacy and Teaching Effort. The analysis makes explicit a distant context from the goals 3, 15, 17 and 18 of the National Education Plan (2014-2024) and makes evident challenges regarding to the universalization of the access, initial training and to the work conditions of the professor in the High School. It suggests that the social quality issue of the High Scholl will not be solved with the curriculum flexibility proposed by the Law Lei 13.415/2017. The social quality requires universalization to the access, mainly for young people from 15 to 17 years old, and to transform the teaching into a social attractive profession. Dimensions are underestimated in discussions on the present time by reformation defenders.
\end{abstract}

Keywords: Initial training. Universalization. Work conditions.

Resumen: El artículo tiene el objetivo de comprender los límites y las perspectivas para universalización del acceso y para valorización del profesor en la Enseñanza Secundaria. La discusión fue basada en indicadores educacionales en relación con la cualidad social, con despegue para la Tasa de Frecuencia Líquida, Adecuación de la Formación y el Esfuerzo Docente. El análisis explicita un 
contexto lejos del propuesto en las metas 3, 15, 17 y 18 del Plan Nacional de Educación (2014-2024), y hace evidente desafíos relacionados con la universalización del acceso, con la formación inicial y con las condiciones de trabajo del profesor de la Enseñanza Secundaria. Sugiere que el problema de la cualidad social de la Enseñanza Secundaria no se va a resolver con la flexibilización curricular propuesta por la Ley 13.415/2017. La cualidad social reivindica la universalización del acceso, principalmente de los jóvenes de 15 a 17 años, y la transformación de la docencia en una profesión socialmente atractiva. Dimensiones son subestimadas en las discusiones del tiempo presente por los defensores de la reforma.

Palabras Clave: Universalización. Formación Inicial. Condiciones de Trabajo.

\section{Introdução}

O debate sobre o Ensino Médio no Brasil, nos últimos vinte e três anos, desde a promulgação da Lei no 9.394 de 1996, que lhe atribuiu estatuto de etapa da Educação Básica, tem sido intenso. As tentativas de reformulação do currículo do Ensino Médio são recorrentes e evidenciam disputas em torno dos sentidos e finalidades do Ensino Médio. Ganha destaque no tempo presente a sanção da Lei $\mathrm{n}^{\circ}$ 13.415/2017, que traz uma proposta de reforma ancorada na flexibilização curricular (KRAWCZYK; FERRETTI, 2017).

A referida legislação coloca holofotes sobre a reforma curricular do Ensino Médio e retira do centro das discussões, a ausência de políticas públicas que promovam sua oferta com qualidade social ${ }^{1}$. A articulação entre as relações sociais mais amplas e as dimensões intraescolares acomodam o conceito de qualidade social do Ensino Médio. Mais especificamente, demanda portas abertas para todos, mormente aos jovens de 15 a 17 anos, professores licenciados nas disciplinas que lecionam e com carreira e condições de trabalho condignas, pautadas na formação humana integral ${ }^{2}$. As dimensões intraescolares referidas são destacadas no Plano Nacional de Educação (PNE), aprovado pela Lei $n^{\mathbf{o}}$ 13.005/2014. A universalização do acesso é pautada na meta 3; a formação inicial, na meta 15; e as condições de trabalho ${ }^{3}$, com destaque as relações de emprego, estão presentes nas metas 17 e 18.

\footnotetext{
${ }^{1} \mathrm{O}$ conceito de qualidade social conforma a articulação entre as dimensões extraescolares e intraescolares. "As primeiras dizem respeito às condições socioeconômicas e culturais, dos direitos e das obrigações e garantias. As segundas referem-se a condições: a) de oferta, de gestão e organização do trabalho nas instituições educativas; b) de valorização, formação, profissionalização e ação pedagógica; c) de acesso, permanência e desempenho escolar e acadêmico" (FÓRUM NACIONAL DE EDUCAÇÃ̃O, 2017, p. 19).

${ }^{2}$ Formação que permita, ao jovem, "entender ampla e criticamente tanto a sociedade em que vivem quanto a forma pela qual se estrutura o trabalho que realizam, tendo em vista a construção de formas mais humanas e igualitárias de produzir e viver" (KRAWCZYK; FERRETTI, 2017, p. 40).

${ }^{3}$ Com base em Oliveira e Assunção (2010), a noção de condições de trabalho designa o conjunto de recursos que possibilitam a realização do trabalho do professor, envolvendo as instalações físicas, os materiais e insumos disponíveis, os equipamentos e meios de realização das atividades pedagógicas. Envolvem, também, no âmbito
} 
Este artigo foca a análise na universalização do acesso, na formação inicial e nas condições de trabalho dos professores, dimensões centrais ao Ensino Médio com qualidade social, com intuito de contribuir com a necessária discussão sobre a última etapa da Educação Básica no domínio das mudanças trazidas pela Lei ${ }^{\circ}$ 13.415/2017. A partir dessas reflexões, problematizou-se: quais os limites e as perspectivas à universalização do acesso, à formação e às condições de trabalho dos professores do Ensino Médio que atuam nas escolas estaduais ${ }^{4}$ no Brasil?

Os subsídios empíricos para a referida problematização foram buscados na Pesquisa Nacional por Amostra de Domicílios (PNAD) e no Censo Escolar da Educação Básica, sobretudo, na Taxa Líquida de Matrícula (TLM) e nos indicadores educacionais Adequação da Formação e Esforço Docente, e nas metas 3, 15,17 e 18 do PNE. Os dados foram cotejados com parte da produção bibliográfica relacionada à temática do estudo. A análise pautou-se nas seguintes categorias de conteúdo: universalização do acesso no Ensino Médio, formação inicial do professor do Ensino Médio e condições de trabalho do professor desta etapa da Educação Básica. Na análise, o objeto de estudo foi tomado na relação inseparável entre o plano estrutural e o conjuntural (FRIGOTTO; CIAVATTA, 2011). Com o referido entendimento, utilizaram-se os pressupostos teórico-metodológicos de imersão nos dados quantitativos e qualitativos, com intuito de ir além da compreensão imediata do Ensino Médio. Buscou-se compreender a universalização e a valorização dos professores do Ensino Médio, explicitando, dialeticamente, suas relações com o contexto econômico, político, social e cultural (NOSELLA; BUFFA, 2005).

\section{Universalização do acesso no Ensino Médio}

A obrigatoriedade e gratuidade da Educação Básica para a faixa etária de 4 a 17 anos está assinalada na Constituição federal, via Emenda Constitucional no 59/2009. Esta conquista significativa tornaria o Ensino Médio obrigatório para os jovens de 15 a 17 anos, idade adequada para frequentá-lo, "não fossem as desigualdades de acesso à escola, os itinerários descontínuos e as distorções no âmbito do sistema educacional” (SILVA, 2015, p. 370).

Percursos formativos instáveis aparecem entre os jovens pertencentes ao grupo de

das relações de emprego, elementos concernentes à carreira docente, com destaque ao vínculo, à remuneração e à jornada de trabalho.

${ }^{4} \mathrm{O}$ foco deste trabalho é analisar aspectos do acesso e da valorização dos professores das escolas estaduais. A dependência administrativa estadual detém aproximadamente $85 \%$ da matrícula nesta etapa da Educação Básica. 
idade 15 a 17 anos que estão fora da escola ou retidos no Ensino Fundamental. Uma situação ideal seria aquela em que todos com idade adequada estivessem no Ensino Médio. Neste caso, a Taxa de Atendimento Escolar (TAE) e a Taxa Líquida de Matrícula (TLM) seriam de $100 \%$. Vale destacar que o primeiro indicador aponta o percentual de jovens matriculados na Educação Básica, e o segundo expressa o percentual de matriculados no Ensino Médio. A Tabela 1 permite avaliar o acesso da população de 15 a 17 anos ao Ensino Médio no Brasil.

Tabela 1 - Aspectos da matrícula na faixa de 15 a 17 anos no Brasil - 1991/2018

\begin{tabular}{l|c|c|c|c}
\hline Ano & $\begin{array}{c}\text { População } \\
(x 1.000)\end{array}$ & $\begin{array}{c}\text { Matrícula } \\
(x 1.000)\end{array}$ & $\begin{array}{c}\text { TAE } \\
(\%)\end{array}$ & $\begin{array}{c}\text { TLM } \\
(\%)\end{array}$ \\
\hline 1991 & 9.275 & 3.773 & 58,1 & 12,5 \\
1999 & 10.395 & 7.769 & 78,5 & 33,4 \\
2005 & 10.646 & 9.031 & 81,7 & 50,7 \\
2011 & 10.580 & 8.401 & 83,7 & 56,0 \\
2013 & 10.642 & 8.313 & 84,3 & 55,2 \\
2014 & 10.547 & 8.300 & 84,3 & 58,6 \\
2015 & 10.600 & 8.100 & 85,0 & 59,1 \\
2016 & 10.618 & 8.133 & 87,2 & 68,2 \\
2017 & 10.426 & 7.930 & 87,2 & 68,5 \\
2018 & 9.752 & 7.709 & 88,2 & 69.3 \\
\hline
\end{tabular}

Fonte: IBGE (2018); BRASIL (2018).

Os números do Ensino Médio brasileiro podem impressionar ao se considerar 9,7 milhões de matrículas em 2018. Por outro lado, evidenciam, nos últimos anos, certa estagnação/acomodação da matrícula e alguns períodos de quedas. Sugerem sua não prioridade nas políticas educacionais, à revelia da Lei $\mathrm{n}^{\circ}$ 9.394/1996, que lhe atribui status de etapa da Educação Básica. Ao considerar que o lugar de jovens do grupo de idade 15 a 17 anos é na escola, que frequentam, preferencialmente, o Ensino Médio e, com base em Saviani (2013), questionam-se os limites e as possibilidades de o Estado brasileiro assumir o dever correlato de garantir a todos esse direito.

A análise da TAE aponta que, nos últimos anos, persiste no Brasil a ocorrência de aproximadamente 1,2 milhões de jovens de 15 a 17 anos fora da escola. Ao mesmo tempo, o exame da TLM permite inferir que praticamente $30 \%$ dos jovens de 15 a 17 anos não estão matriculados no Ensino Médio. Explicita que, além dos jovens que estão fora da escola, cerca 
de 1,8 milhões estão retidos no Ensino Fundamental. Estes números revelam que 3,0 milhões de jovens pertencentes ao grupo de idade 15 a 17 anos não estavam matriculados no Ensino Médio. Logo, estão impedidos de se apropriar dos conhecimentos científicos historicamente produzidos, "profunda contradição, diante da presença das ciências e da tecnologia na vida cotidiana" (FRIGOTTO; CIAVATTA, 2011, p. 620).

Esses brasileiros perdem a oportunidade de vivenciar integralmente a adolescência, durante a qual, por meio de experiências orientadas, eles se definem moral, intelectual e socialmente (NOSELLA, 2011). Para o referido autor, os milhões de jovens que não frequentam o Ensino Médio no tempo apropriado não usufruem do momento catártico mais delicado e importante de suas vidas, quando desabrocha o valor da autonomia, que é a liberdade de se posicionar. Com base em Gramsci, Nosella (2011) defende que o Ensino Médio deve ser frequentado e concluído por todos os jovens do grupo de idade 15 a 17 anos, período da vida juvenil em que se consolidam os valores fundamentais do humanismo, a autodisciplina intelectual e a autonomia moral fundamentais às especializações futuras.

O Brasil tem uma grande dívida com os jovens. Como possiblidade importa ganhar visibilidade e ser materializada a meta 3 do PNE, que estabelece:

Universalizar, até 2016, o atendimento escolar para toda a população de 15 (quinze) a 17 (dezessete) anos e elevar, até o final do período de vigência deste PNE, a taxa líquida de matrículas no ensino médio para $85 \%$ (oitenta e cinco por cento) (BRASIL, 2014).

A universalização do atendimento escolar para todos da faixa etária 15 a 17 anos estava indicada para 2016, e não se materializou. Em 2016 estavam matriculados, na Educação Básica, apenas 8,7 milhões desses jovens (BRASIL, 2018). Tratava-se, e ainda se trata, de um passo necessário trazer todos para a escola com celeridade. Resultado semelhante poderá ser verificado com a TLM em 2024. A reedição de anualmente aproximadamente 1,2 milhões de jovens pertencentes ao grupo de idade 15 a 17 anos não frequentarem nenhuma escola é incompatível com a qualidade social que se quer para a Educação. Ao mesmo tempo, também é imprescindível citar a possibilidade de muitos permanecerem retidos no Ensino Fundamental.

De forma contraditória, não se vislumbra, com a Lei $n^{\circ} 13.415 / 17$, assegurar a todos os brasileiros do grupo de idade 15 a 17 anos o direito do acesso ao Ensino Médio nos próximos anos. A palavra de ordem que se evidencia a partir de 2016, com base no conjunto de mudanças contidas na MP n 746/16, transformada com algumas alterações na referida Lei, é flexibilização (KRAWCZYK; FERRETI, 2017). A ênfase dos argumentos dos seus 
propositores é aproximar a "última etapa da educação básica a uma visão mercantil da escola pública e contrariam seu caráter público, inclusivo e universal” (SILVA; SCHEIBE, 2017, p. 28). A universalização não é pauta. A flexibilização curricular proposta não se compromete em "assegurar o direito de cada brasileiro, provendo uma educação com o mesmo padrão de qualidade a toda a população" (SAVIANI, 2013, p. 755).

Por outro lado, o entendimento legal que o lugar de todos os jovens é na escola implica diminuir a distância entre a Educação Básica proclamada como direito e as responsabilidades dos entes federados, "de prover os meios para que o referido direito se efetive. Eis porque se impôs o entendimento de que a educação é direito do cidadão e dever do Estado" (SAVIANI, 2013, p. 745). Praticamente cinco décimos da vigência do PNE já se passaram. O primeiro objetivo da meta 3 não foi alcançado e sugere dar "efetividade à bandeira da escola pública universal, obrigatória, gratuita e laica" (SAVIANI, 2013, p. 745). O proposto justifica-se quando se constata que aproximadamente 3,0 milhões de jovens pertencentes ao grupo de 15 a 17 anos não estavam matriculados no Ensino Médio em 2018.

A sistemática negação do acesso e da permanência no Ensino Médio revela o desafio dos entes federados para levar a cabo o que a meta do PNE fixa para o atendimento até 2024. Vislumbra-se que sejam oferecidas, a todos os jovens, "condições educativas para o aprendizado intelectual, o qual pressupõe denso tempo de leitura, laboratórios, espaço de lazer, arte e cultura" (FRIGOTTO; CIAVATTA, 2011, p. 620). Estas demandas trazem novos desafios aos docentes que, segundo Oliveira (2014, p. 451), “devem também estar em condições de desenvolver a autonomia dos alunos e o seu interesse em seguir aprendendo ao longo da vida". Para enfrentar este desafio, as condições oferecidas aos docentes "não são muitas vezes minimamente adequadas em termos materiais, menos ainda em dimensões subjetivas, que precisam ser cada vez mais observadas” (OLIVEIRA, 2014, p. 451).

O cumprimento da meta 3 exige ações que neguem a flexibilização proposta na Lei $n^{\circ}$ 13.415/17 (LIMA; MACIEL, 2018). Para além de uma mudança curricular, importa a "aquisição de equipamentos, material didático, formação continuada de professores, adoção de programas de correção de fluxo escolar, universalização do Exame Nacional do Ensino Médio (ENEM) e ampliação de matrículas” (LIMA; MACIEL, 2018, p. 8). Um contexto de mais alunos e mais professores suscita problematizar a formação dos professores da última etapa da Educação Básica. Este aspecto é central na busca da qualidade social do Ensino Médio, e também não foi pautado pelos arautos da reforma. 


\section{Formação inicial do professor no Ensino Médio}

O acesso às etapas da Educação Básica e a valorização dos profissionais da Educação foram contemplados na Lei $n^{\circ} 13.005 / 2014$, que aprovou o Plano Nacional de Educação (PNE) para o decênio 2014-2024. A partir da discussão realizada anteriormente, cabe problematizar a valorização dos profissionais da Educação, compreendida como envolvendo, de forma articulada, formação, remuneração, carreira e condições de trabalho e saúde (FÓRUM NACIONAL DE EDUCAÇÃO, 2017). No que tange à formação inicial, os limites são evidentes, como mostra na tabela 2.

Tabela 2 - Professores do Ensino Médio do Brasil segundo a formação acadêmica $2013 / 2018$

\begin{tabular}{|c|c|c|c|c|c|}
\hline Ano & Total & Formação superior & $(\%)$ & Com $^{5}$ licenciatura & $(\%)$ \\
\hline 2013 & 509.403 & 472.450 & 92,8 & 435.369 & 85,5 \\
2014 & 524.315 & 487.321 & 92.9 & 454.644 & 86,7 \\
2015 & 522.826 & 484.857 & 92,7 & 449.781 & 86,0 \\
2016 & 519.883 & 484.785 & 93,2 & 448.890 & 86,3 \\
2017 & 509.814 & 476.626 & 93,5 & 442.274 & 86,8 \\
2018 & 513.403 & 482.269 & 93,9 & 454.849 & 88,6 \\
\hline
\end{tabular}

Fonte: BRASIL (2018).

Percebe-se, ao longo do interregno 2013-2018, um percentual expressivo de sujeitos que lecionam no Ensino Médio com Ensino Superior. Verifica-se uma acomodação ao redor dos 94,0\% que possuem graduação. Por outro lado, a falta de professores com formação adequada para lecionar nas escolas de Ensino Médio é evidente. Entende-se que não basta cursar um determinado curso superior para ser professor. Considera-se professor do Ensino Médio os que possuem, como formação acadêmica, uma licenciatura. Os dados apontam para a manutenção de $88 \%$ dos professores do Ensino Médio com licenciatura ou com complementação pedagógica. Expressam a possibilidade de $12 \%$ lecionarem sem ser professores, por não estarem habilitados para exercer a docência. Importa que todos os professores do Ensino Médio sejam licenciados.

\footnotetext{
${ }^{5}$ Inclui cursos de complementação pedagógica.
} 
Com base na Lei de Diretrizes e Bases da Educação no 9.394/96 (LDB), sem a licenciatura não são considerados professores. Tal compreensão amplia-se quando se considera, entre outros fatores, segundo Kuenzer (2011, p. 671), "a desigualdade da distribuição da qualificação entre as disciplinas, fato que vem sendo reiteradamente apontado nas últimas décadas. Assim, apenas $53 \%$ dos professores que atuam no ensino médio têm formação compatível com a disciplina que lecionam”. Neste contexto, baseia-se o proposto pela meta 15 do PNE, que enuncia assegurar a "todos os professores e as professoras da educação básica possuam formação específica de nível superior, obtida em curso de licenciatura na área de conhecimento em que atuam" (BRASIL, 2014). Ganha visibilidade o professor com formação na disciplina que leciona. Com intuito de contribuir com a materialização da meta 15, o Instituto Nacional de Estudos e Pesquisas Educacionais Anísio Teixeira (INEP) constrói o Indicador de adequação da formação do docente da Educação Básica que distribui o docente, com base em sua formação, em cinco grupos, conforme mostra o quadro 1.

Quadro 1 - Categorias de adequação da formação dos docentes em relação à disciplina que leciona

\begin{tabular}{|l|l|}
\hline GRUPO & DESCRIÇÃO \\
\hline 01 & $\begin{array}{l}\text { Docentes com formação superior de licenciatura na mesma disciplina que } \\
\text { lecionam, ou bacharelado na mesma disciplina com curso de complementação } \\
\text { pedagógica concluído. }\end{array}$ \\
\hline 02 & $\begin{array}{l}\text { Docentes com formação superior de bacharelado na disciplina correspondente, } \\
\text { mas sem licenciatura ou complementação pedagógica. }\end{array}$ \\
\hline 03 & $\begin{array}{l}\text { Docentes com licenciatura em área diferente daquela que leciona, ou com } \\
\text { bacharelado nas disciplinas da base curricular comum e complementação } \\
\text { pedagógica concluída em área diferente daquela que leciona. }\end{array}$ \\
\hline 04 & Docentes com outra formação superior não considerada nas categorias anteriores. \\
\hline 05 & Docentes que não possuem curso superior completo. \\
\hline
\end{tabular}

Fonte: BRASIL (2018a).

Ao considerar o enunciado da meta 15 , a proporção de docentes no grupo 1 poderia ser a métrica utilizada para acompanhá-la (BRASIL, 2018a, p. 5). Com base no referido indicador, pode-se constatar, na tabela 3 que, no período 2013-2018, a manutenção de aproximadamente 40,0\% dos professores do Ensino Médio da dependência administrativa 
estadual sem formação para compor o grupo 1 nas escolas. Trata-se de profissionais que não possuíam licenciatura na mesma disciplina que lecionam, ou bacharelado na mesma disciplina com curso de complementação pedagógica concluído.

Tabela 3 - Percentual de docentes no Ensino Médio por grupo do indicador de adequação da formação Docente, segundo dependência administrativa Estadual- Brasil - 2013-2018

\begin{tabular}{lllllll}
\hline Ano & Abrangência & Grupo 1 & Grupo 2 & Grupo 3 & Grupo 4 & Grupo 5 \\
\hline $\mathbf{2 0 1 3}$ & Estadual & 56,9 & 3,9 & 25,5 & 7,0 & 6,7 \\
$\mathbf{2 0 1 4}$ & Estadual & 58,7 & 2,7 & 25,5 & 6,7 & 6,4 \\
$\mathbf{2 0 1 5}$ & Estadual & 58,0 & 3,1 & 25,6 & 6,8 & 6,5 \\
$\mathbf{2 0 1 6}$ & Estadual & 59,7 & 3,1 & 24,8 & 6,8 & 5,6 \\
$\mathbf{2 0 1 7}$ & Estadual & 60,4 & 3,0 & 24,9 & 6,3 & 5,4 \\
$\mathbf{2 0 1 8}$ & Estadual & 61,3 & 2,1 & 26,0 & 5,8 & 4,8 \\
\hline
\end{tabular}

Fonte: BRASIL (2018a).

Os dados mostram que, para atender à meta 15 , é necessário ampliar de $61,3 \% \mathrm{em}$ 2018 para $100 \%$ até o final da vigência do PNE o percentual de professores com licenciatura nas disciplinas sob sua responsabilidade. No período analisado, verificou-se um tímido aumento de 4,4\% de professores pertencentes ao Grupo 1, e expressa "o grande desafio de garantir a formação, em nível superior" (DOURADO, 2016, p. 39), preconizado na referida meta. O autor destaca a necessidade de políticas para a formação, que superem a forte presença de professores com licenciatura em uma determinada disciplina ou área e que "atuam em área distinta, muitas das vezes para complementar a carga horária".

Para além da escassez de professores, questiona-se a qualidade da formação docente (KUENZER, 2011). As licenciaturas não podem desconsiderar a juventude que frequenta e que frequentará a última etapa da Educação Básica. É importante que na formação inicial, sejam previstos "conhecimentos pedagógicos, compreendendo a articulação entre estudos teórico-práticos, investigação e reflexão crítica, aproveitamento da formação e experiências anteriores em instituições de ensino" (DOURADO, 2015, p. 308). Ao futuro professor do Ensino Médio sugere-se um mergulho "no universo da escola e da sala de aula e que o fortaleça por meio de uma sólida formação teórica e prática" (SILVA, 2015, p. 72). Neste âmbito, destaca-se a estratégia 15.6 da meta 15, que aponta "promover a reforma curricular dos cursos de licenciatura e estimular a renovação pedagógica" (BRASIL, 2014). 
A ausência de professores habilitados e a qualidade da formação justificam-se, segundo Kuenzer (2011, p. 672), pela baixa atratividade da carreira docente. Tal compreensão é corroborada por Saviani (2011, p. 16), ao enfatizar que não é possível "equacionar devidamente o problema da formação dos professores sem enfrentar simultaneamente a questão das condições de exercício do trabalho docente. Isso porque, de fato, esses dois aspectos se articulam e se relacionam na forma de ação recíproca". Retomar a expansão da matrícula do Ensino Médio implica ampliar o número de professores com licenciatura nas disciplinas que lecionam. Demanda, também, acento nas demais dimensões da valorização dos profissionais da Educação. Condições necessárias para enfrentar uma histórica realidade de escassez, inadequação e desprofissionalização do professor, "com seus severos impactos sobre a qualidade do ensino médio, cujas matrículas decrescem a cada ano, assim como não melhoram os indicadores de permanência e de sucesso" (KUENZER, 2011, p. 675).

De forma contraditória, ganha destaque com a Lei $n^{\circ}$ 13.415/2017 uma mudança legal que altera o currículo e silencia aspectos relacionados à valorização dos professores. Ao mesmo tempo, quando toca no professor fragiliza-o com o reconhecimento, por exemplo, do notório saber. O consentimento "de que professores sem formação específica assumam disciplinas no itinerário da formação técnica e profissional institucionaliza a precarização da docência e compromete a qualidade dessa formação" (SILVA, 2017, p. 22). A instituição do notório saber, na referida, Lei "representa uma tentativa do governo de resolver problemas estruturais do ensino médio, como a falta de professores em determinadas áreas e o custo que eles representam" (LIMA; MACIEL, 2018, p. 19). O problema da falta de professores do Ensino Médio pode estar relacionado à carreira, ao baixo nível de remuneração e ao número excessivo de turnos, turmas, aulas e alunos. Destaca-se a centralidade das condições de trabalho, considerada essencial quando se discute a valorização dos profissionais da educação (FÓRUM NACIONAL DE EDUCAÇÃO, 2017).

\section{Condições de trabalho do professor no Ensino Médio}

No âmbito das condições de trabalho, interessam as relações de emprego, com destaque ao tipo de vínculo, jornada de trabalho, remuneração e formação, vinculados à carreira (PINTO; DUARTE; VIEIRA, 2012). Importa que as políticas educacionais articulemse para garantir “[...] maior tempo remunerado para os docentes nas escolas, permitindo o desenvolvimento de maiores vínculos com seu trabalho e, logo, maior tempo de dedicação à educação desses jovens" (OLIVEIRA, 2010, p. 275). Tais compreensões são corroboradas por 
Saviani (2011, p. 16), ao enfatizar que não é possível equacionar devidamente os problemas educacionais sem enfrentar simultaneamente "a questão das condições de exercício do trabalho docente".

No PNE, aspectos relacionados às condições de trabalho estão diluídos nas diferentes metas e estratégias. A meta $18^{6}$, em sua estratégia 18.1, destaca a preocupação com o vínculo do professor, ao propor

[...] estruturar as redes públicas de educação básica de modo que, até o início do terceiro ano de vigência deste PNE, noventa por cento, no mínimo, dos respectivos profissionais do magistério [...] sejam ocupantes de cargos de provimento efetivo e estejam em exercício nas redes escolares a que se encontrem vinculados (BRASIL, 2014).

O ingresso do professor do Ensino Médio na carreira docente ainda está muito distante do preconizado na referida estratégia. A tabela 4 demonstra o número de professores efetivos do Ensino Médio da rede pública de ensino.

Tabela 4 - Professores do Ensino Médio público efetivos, segundo as dependências administrativas - Brasil - 2013/2018

\begin{tabular}{lllllll}
\hline Ano & Total & Efetivos & Federal & Estadual & Municipal & Total\% \\
\hline 2013 & 425.940 & 301.996 & 14.490 & 284.351 & 4.262 & 70,9 \\
2014 & 439.561 & 309.603 & 15.640 & 291.254 & 3.732 & 70.9 \\
2015 & 438.946 & 304.641 & 17.903 & 284.174 & 3.525 & 69,4 \\
2016 & 435.049 & 299.136 & 20.528 & 276.087 & 3.409 & 68,6 \\
2017 & 424.463 & 294.633 & 22.498 & 269.706 & 3.188 & 69,4 \\
2018 & 427.421 & 277.712 & 23.927 & 251.731 & 2.683 & 65,0 \\
\hline
\end{tabular}

Fonte: Brasil (2018).

Os dados indicam que em 2018 aproximadamente 35\% dos professores do Ensino Médio público não são concursados, mas possuem contrato, em sua maioria temporário, além do terceirizado ou Celetista. Ao apresentar um número expressivo de professores com contratos temporários de forma persistente, evidencia-se, com base em Oliveira (2006), certa precarização nos aspectos concernentes às relações de emprego oferecidas. Os contratos

\footnotetext{
6 “Assegurar, no prazo de dois anos, a existência de planos de carreira para os (as) profissionais da educação básica e superior pública de todos os sistemas de ensino e, para o plano de carreira dos (as) profissionais da educação básica pública, tomar como referência o piso salarial nacional profissional, definido em lei federal, nos termos do inciso VIII do art. 206 da Constituição Federal” (BRASIL, 2014c).
} 
temporários são desprovidos de garantias trabalhistas e previdenciárias e, por não assegurarem os mesmos direitos e garantias dos professores efetivos, tornam "cada vez mais agudo o quadro de instabilidade e precariedade do emprego" (OLIVEIRA, 2006, p. 216). Não pertencer ao quadro dos efetivos exclui os professores "da complexidade da dinâmica da escola e das relações no interior da mesma, devido sua transitoriedade, limitam a sua participação e envolvimento na construção do projeto educativo da escola" (CAMARGO et al., 2006, p. 260).

Por outro lado, uma carreira estável pode tornar a profissão docente mais atraente, ao possibilitar, segundo Camargo et al. (2006, p. 260), "uma maior segurança para a realização de seu trabalho, uma vez que não estaria sujeito a demissões ao final de licenças, de contratos ou ao final do ano". Com base nos autores, infere-se que a estabilidade trabalhista, o ingresso em uma carreira docente definida e a realização de seu trabalho com maior segurança, sugerem melhores perspectivas às condições de oferta de um Ensino Médio de qualidade social.

O número expressivo de professores do Ensino Médio público brasileiro com contratos temporários pode ser explicado pela dimensão econômica. Há estreita vinculação entre a forma de contratação e a remuneração dos profissionais da Educação. Os professores temporários têm menores remunerações. No Brasil, não se remunera adequadamente os professores efetivos, menos ainda os temporários (OLIVEIRA, 2006).

Valorizar os professores do Ensino Médio seria a natural opção política de um Estado (União, Estados da Federação e Distrito Federal) realmente comprometido com a qualidade social dessa etapa da Educação Básica (KUENZER, 2010). Ao considerar os 404.488 professores que lecionam nas escolas estaduais do Brasil (BRASIL, 2018), espera-se que sejam licenciados, efetivos e possuam condições de trabalho adequadas, como sugere a Lei ${ }^{\circ}$ 11.738/08 (BRASIL, 2008), que instituiu o Piso Salarial Profissional Nacional (PSPN) para os profissionais do magistério público da Educação Básica com formação em nível médio, na modalidade Normal, para jornada de, no máximo, 40 (quarenta) horas semanais. Na composição da jornada de trabalho, destaca-se o limite máximo de $2 / 3$ (dois terços) da carga horária para o desempenho das atividades de interação com os educandos.

Não obstante, levantamento realizado em 2016 pela Confederação Nacional dos Trabalhadores em Educação (CNTE) explicita que a referida lei não é cumprida nos quesitos Piso e Jornada Extraclasse por seis dos estados da federação: Amazonas, Goiás, Maranhão, Paraíba, Rio Grande do Sul e São Paulo. Destaca-se, também, que a aplicação da Lei do Piso tem registrado prejuízos às carreiras do magistério, ofendendo, assim, o dispositivo 
constitucional (art. 206, V), que preconiza a valorização dos profissionais da educação por meio de planos de carreira que atraiam e mantenham os trabalhadores nas escolas públicas, contribuindo para a melhoria da qualidade da educação (CNTE, 2016). O cumprimento da Lei $\mathrm{n}^{\circ}$ 11.738/08 remete à meta 17 , que propõe "valorizar os (as) profissionais do magistério das redes públicas de educação básica de forma a equiparar seu rendimento médio ao dos (as) demais profissionais com escolaridade equivalente, até o final do sexto ano de vigência deste PNE” (BRASIL, 2014).

Para Masson (2016, p. 161), “a equiparação salarial do professor com as demais profissões é condição indispensável para a atratividade e permanência na carreira, pois é a questão que mais determina a escolha dos jovens, embora isso não seja suficiente". A autora destaca que a remuneração dos professores tem melhorado com a aprovação do PSPN. Por outro lado, aponta que muitos estados da federação têm considerado o valor mínimo como se fosse o máximo.

As disparidades estaduais no que tange à valorização dos professores sugerem a construção de um Sistema Nacional de Educação (SNE), com ampla colaboração dos estados da federação para usar da prerrogativa de sua autonomia para valorizar seus professores. A inexistência de um SNE permite que as políticas educacionais movimentem-se nos diferentes estados, por exemplo, com planos de carreira e remunerações distintas entre os professores; infraestrutura instalada com padrões diferentes; e propostas pedagógicas diversas (GOUVEIA; PINTO; CORBUCCI, 2011).

Este contexto adverso manifesta-se na rotatividade de professores, na multiplicidade de vínculos empregatícios, e na decorrente extensão da jornada de trabalho docente, opondose à qualidade social do Ensino Médio brasileiro. A valorização salarial com a garantia de satisfação das necessidades básicas a partir de seu salário mensal recebido da rede de ensino a que está vinculado pode permitir, por exemplo, que os professores do Ensino Médio dediquem-se a uma determinada escola, e com tempo disponível para elaborar suas aulas. Para Saviani (2011, p. 16), a qualidade do trabalho pedagógico eleva-se com "jornada de trabalho de tempo integral em uma única escola com tempo para aulas, preparação de aulas, orientação de estudos dos alunos, participação na gestão da escola e reuniões de colegiados e atendimento à comunidade".

Nesse âmbito, o INEP constrói o indicador Esforço Docente, que mensura o esforço empreendido pelos docentes da Educação Básica brasileira no exercício de sua profissão (BRASIL, 2018b). Considera o número de turnos de trabalho, escolas e etapas de atuação, além da quantidade de alunos atendidos na Educação Básica, e articula-se à jornada de 
trabalho. O quadro 2 apresenta a descrição dos níveis baseada na distribuição empírica das variáveis.

Quadro 2 - Níveis de esforço docente

\begin{tabular}{|l|l|}
\hline NÍVEL & DESCRIÇÃO \\
\hline 01 & Docente que tem até 25 alunos e atua em um único turno, escola e etapa. \\
\hline 02 & $\begin{array}{l}\text { Docente que tem entre } 25 \text { e } 150 \text { alunos e atua em um único turno, escola e etapa. } \\
\text { escola e etapa. }\end{array}$ \\
\hline 03 & $\begin{array}{l}\text { Docente que tem entre } 50 \text { e } 400 \text { alunos e atua em dois turnos, em uma ou duas } \\
\text { escolas e em duas etapas. }\end{array}$ \\
\hline 04 & $\begin{array}{l}\text { Docente que tem mais de } 300 \text { alunos e atua nos três turnos, em duas ou três } \\
\text { escolas e em duas etapas ou três etapas. }\end{array}$ \\
\hline 06 & $\begin{array}{l}\text { Docente que tem mais de } 400 \text { alunos e atua nos três turnos, em duas ou três } \\
\text { escolas e em duas etapas ou três etapas. }\end{array}$ \\
\hline
\end{tabular}

Fonte: BRASIL (2018b).

Não obstante a tentativa de abarcar as duas últimas etapas da Educação Básica, considera-se que o indicador Esforço Docente apresenta limites para a compreensão do Ensino Médio. Qual nível poderia ser a métrica utilizada para acompanhar as estratégias do PNE relacionadas aos aspectos das condições de trabalho do Ensino Médio? No entanto, os níveis 05 e 06 expressam claramente a intensificação do trabalho docente ${ }^{7}$.

Os dados de 2018 apresentados na tabela 5 mostram que $16,6 \%$ dos professores do Ensino Médio que lecionam nas escolas estaduais no Brasil têm mais de 300 alunos e atuam nos três turnos, em duas ou três escolas e em duas ou três etapas. Um esforço docente maior é dispendido por $8,3 \%$, que trabalham com mais de 400 alunos e atuam nos três turnos, em duas ou três escolas e em duas ou três etapas.

\footnotetext{
${ }^{7}$ Para Oliveira (2006), a intensificação do trabalho docente resulta da ampliação da jornada de trabalho e do aumento considerável de responsabilidades que os docentes tiveram com as reformas mais recentes. Com base na autora, a intensificação do trabalho docente pode ser intensa, com a ampliação das funções/tarefas; e/ou extensa, com a ampliação da jornada de trabalho.
} 
Tabela 5 - Percentual de docentes que atuam no Ensino Médio por níveis do indicador de esforço docente, segundo localização e dependência administrativa Estadual - Brasil - 20132018

\begin{tabular}{llllllll}
\hline Ano & Abrangência & Nível 1 & Nível 2 & Nível 3 & Nível 4 & Nível 5 & Nível 6 \\
\hline 2013 & Estadual & 0,6 & 7,1 & 21,8 & 45,0 & 17,1 & 8,4 \\
2014 & Estadual & 0,7 & 7,5 & 22,4 & 44,9 & 16,4 & 8,1 \\
2015 & Estadual & 0,8 & 7,4 & 22,0 & 45,3 & 16,7 & 7,8 \\
2016 & Estadual & 0,9 & 7,2 & 21,5 & 45,6 & 16,7 & 8,1 \\
2017 & Estadual & 0,8 & 7,0 & 22,0 & 45,2 & 16,8 & 8,2 \\
2018 & Estadual & 0,9 & 7,3 & 22,2 & 44,7 & 16,6 & 8,3 \\
\hline
\end{tabular}

Fonte: BRASIL (2018b).

Ressalta-se que, no interregno 2013 a 2018, aproximadamente $25 \%$ dos professores do Ensino Médio das escolas estaduais concentraram-se nos níveis 05 e 06, o que revela uma jornada extensa e intensa. Trabalhar em mais de uma escola, em três turnos com muitos alunos de diferentes etapas da Educação Básica faz parte do cotidiano de uma parcela expressiva dos professores da última etapa da Educação Básica, que lecionam nas escolas estaduais no Brasil. Os dados explicitam a persistência da grande concentração de professores com mais de 300 alunos e atuando nos três turnos, em duas ou três escolas e em duas ou três etapas.

A dedicação a uma escola e de jornadas não exaustivas parece não ser uma realidade dos professores do Ensino Médio. Por outro lado, sua conquista resulta, segundo Camargo et al. (2006) "numa satisfação que, além de promover condições para uma oferta de ensino de qualidade, evita prejuízos à saúde do trabalhador e permite tempo para aqueles interessados em processos complementares de qualificação profissional”. Como contraponto a uma jornada de trabalho com muitas escolas, turnos e alunos, destaca-se a estratégia 17.3 contida no PNE, que incorpora as conquistas da Lei $\mathrm{n}^{\mathrm{o}} 11.738$ :

[...] implementar, no âmbito da União, dos Estados, do Distrito Federal e dos Municípios, planos de Carreira para os (as) profissionais do magistério das redes públicas de educação básica, observados os critérios estabelecidos na Lei $\mathrm{n}^{\circ} 11.738$, de 16 de julho de 2008, com implantação gradual do cumprimento da jornada de trabalho em um único estabelecimento escolar. (BRASIL, 2014). 
A materialização do proposto nas metas do PNE poderá representar maior valorização social do professor (MASSON, 2016). Considera-se, ainda, a complexidade do currículo do Ensino Médio com treze componentes curriculares distribuídos em vinte e cinto aulas semanais, e os limites de um professor cumprir sua carga horária em um único estabelecimento. Todavia, com base em Camargo et al. (2016), a construção da possibilidade de os professores das escolas estaduais do Ensino Médio se dedicarem a somente uma escola está vinculada a todas as dimensões da valorização dos profissionais da educação: em outras palavras, articula-se com a formação, a carreira, a remuneração e as condições de trabalho.

A discussão sobre aspectos das condições de trabalho articula-se à qualidade social do Ensino Médio. Alves e Pinto (2011, p. 633) lembram que a conquista de uma escola pública de qualidade para todos passa por uma adequada jornada de trabalho, que contemple "hora de trabalho extraclasse a ser cumprida na escola e estimule a dedicação exclusiva à docência e, preferencialmente, em uma única escola". A este componente, os autores incorporam a remuneração adequada. Para os autores, equacionados esses dois componentes, "as condições necessárias, embora não suficientes, para um salto de qualidade na educação básica estarão dadas" (ALVES; PINTO, 2011, p. 633).

No âmbito do Ensino Médio, os indicadores visitados mostraram que a qualidade social está para ser conquistada. No Brasil é comum Jovens fora da escola e do Ensino Médio, professores sem formação adequada e com jornadas de trabalho intensas e extensas "esfacelados em seus tempos trabalhando em duas ou três escolas em três turnos para comporem um salário que não lhes permite ter satisfeitas as suas necessidades básicas" (FRIGOTTO, 2016, p. 3). As mudanças no Ensino Médio não podem ignorar a urgência e a relevância de incluir todos os jovens de 15 a 17 anos no Ensino Médio. Da mesma forma, silenciar sobre a inadequada formação e condições de trabalho docente. A reforma contida na Lei $\mathrm{n}^{\mathrm{o}}$ 13.415/2017 silencia “que as escolas não possuem as condições básicas de funcionamento institucional nem do exercício do trabalho dos professores, oferecendo aos estudantes condições dignas de aprendizagem" (KRAWCZYK; FERRETTI, 2017, p. 38), aspectos absolutamente indispensáveis, a qualidade social do Ensino Médio.

Como possiblidades, na perspectiva da qualidade social do Ensino Médio (KUENZER, 2010), sem desconsiderar suas vicissitudes, enfatiza-se o PNE, que aponta, nas metas que tratam da universalização do aceso e da valorização dos profissionais da educação, perspectivas virtuosas também para a última etapa da Educação Básica. Sua conquista suscita a materialização de políticas públicas regulares, que "promovam sua oferta universalizada e de qualidade como direito a ser garantido a todos os brasileiros" (MORAES, 2017, p. 423). 
De forma contraditória, essas questões não estão no radar da reforma. Os propositores da reforma do Ensino Médio são omissos, no que tange à "inexistência de quadro de professores e demais trabalhadores da educação contratados por concurso público; planos de carreiras e de formação, salários dignos e condições de trabalho adequadas” (MOURA; LIMA FILHO, 2017, p. 120).

\section{Considerações}

Neste artigo procurou-se problematizar as categorias de conteúdo universalização do acesso, formação inicial e condições de trabalho do professor no Ensino Médio nas escolas estaduais e os desafios à materialização das metas 3, 15, 17 e 18 do PNE.

No âmbito da universalização do acesso, há um problema quantitativo a ser superado: reiteradamente, aproximadamente 3,0 milhões de jovens de 15 a 17 anos não frequentam o Ensino Médio. A qualidade social não será alcançada sem a efetivação do atendimento escolar para todos da faixa etária 15 a 17 anos. Proposto em Lei para 2016, ainda não se materializou e importa que seja priorizado. A TAE no patamar de $100 \%$ contribuirá para elevar a TLM para $85 \%$ até 2024 , como propõe a meta 3 . A persistência, a cada ano, de aproximadamente 1,2 milhões de jovens pertencentes ao grupo de idade 15 a 17 anos não frequentarem nenhuma escola, e de 1,8 milhões retidos no Ensino Fundamental não condiz com a conquista de uma Educação de qualidade social no Brasil, que se quer republicana - pública, gratuita e para todos.

Com relação à formação inicial, os dados mostram a dimensão do esforço para materializar a meta 15 no PNE. No que diz respeito à escolaridade, ressalta-se o percentual expressivo de professores com formação em nível superior. Por outro lado, ao desagregar os dados relacionados à formação inicial, destacam-se limites quantitativos, mormente, da dependência administrativa estadual, expressos pelo indicador adequação da formação docente. Evidencia a necessidade de elevar, de aproximadamente $60 \%$ para $100 \%$, o percentual de professores do Ensino Médio das escolas estaduais com formação superior de licenciatura na mesma disciplina que leciona, ou bacharelado na mesma disciplina com curso de complementação pedagógica.

No que tange às condições de trabalho, ao considerar o número crescente de professores nos últimos anos e o contingente de 404.488 em 2018, os indicadores educacionais visitados revelam entraves e desafios relacionados à valorização dos profissionais que lecionam no Ensino Médio em escolas estaduais no Brasil. Os dados 
apontaram que o Ensino Médio convive com professores não concursados, que trabalham em muitas escolas, com muitas turmas, alunos, etapas e turnos. $\mathrm{O}$ estudo sugere que as condições de trabalho no Ensino Médio são muito desiguais, verificadas, por exemplo, em redes estaduais de ensino que sequer cumprem a Lei $n^{\circ} 11.738 / 2008$ nos quesitos vencimento básico e carga horária. Realça-se, mesmo com os limites do indicador Esforço Docente, que 1/4 dos professores das escolas estaduais têm mais de 300 alunos e atuam nos três turnos, em duas ou três escolas e em duas etapas ou três etapas.

O Brasil tem uma grande dívida com os jovens e com os profissionais da Educação. O compromisso e a concretização das metas 3, 15,17 e 18 do PNE mostram-se fundamentais. A qualidade social do Ensino Médio só será materializada com todos os jovens na escola frequentando o Ensino Médio e a efetiva valorização dos profissionais da Educação, consubstanciada na formação, remuneração, carreira e condições de trabalho adequadas. Somente com todos os professores valorizados e prestigiados, e com sólida formação teórica, pode-se vislumbrar a garantia, a todos os jovens brasileiros, do direito social à conclusão do Ensino Médio.

A materialização da qualidade social do Ensino Médio sugere mais recursos financeiros para a Educação, e não o contrário. Considera-se igualmente fundamental a institucionalização de um SNE e da aplicação de $10 \%$ do PIB em educação pública. O problema da qualidade social do Ensino Médio, colocado com muita intensidade no centro das discussões com a sanção da Lei 13.415/2017, não se resolverá com a flexibilização curricular proposta. A qualidade social do Ensino Médio reivindica a universalização do acesso, mormente aos jovens de 15 a 17 anos, e a transformação da docência em uma profissão socialmente atraente. Dimensões importantes, ausências silenciadas pelos defensores da reforma.

\section{REFERÊNCIAS}

ALVES, Thiago; PINTO, José Marcelino de Rezende. Remuneração e características do trabalho docente no Brasil: um aporte. Cadernos de Pesquisa, São Paulo, v. 41, p. 606-639, 2011.

BRASIL. Lei de Diretrizes e Bases da Educação Nacional. Lei nº 9.394 de 20 de dezembro de 1996.

BRASIL. Lei no 11.738, de 16 de julho de 2008. Regulamenta a alínea "e" do inciso III do caput do art. 60 do Ato das Disposições Constitucionais Transitórias, para instituir o piso 
salarial profissional nacional para os profissionais do magistério público da educação básica. 2008.

BRASIL. Lei no 13.005, de 25 de junho de 2014. Aprova o Plano Nacional de Educação PNE e dá outras providências. Diário Oficial da União, Brasília, DF, 2014.

BRASIL. Lei No 13.415 de 16 de fevereiro de 2017. Institui a Política de Fomento à Implementação de Escolas de Ensino Médio em Tempo Integral. Brasília, DF, 2017.

BRASIL. Censo Escolar da Educação Básica, 1995 a 2018. Ministério da Educação. Instituto Nacional de Estudos e Pesquisas Educacionais. Brasília: MEC/INEP, 2018.

BRASIL. Indicador Adequação da Formação Docente da educação básica. Instituto Nacional de Estudos e Pesquisas Educacionais Anísio Teixeira Diretoria de Estatísticas Educacionais. Nota Técnica n ${ }^{\circ}$ 020/2014. Brasília, 2018a.

BRASIL. Indicador de Esforço Docente. Instituto Nacional de Estudos e Pesquisas Educacionais Anísio Teixeira Diretoria de Estatísticas Educacionais. Nota Técnica ${ }^{\circ}$ 039/2014. Brasília, 2018b.

CAMARGO, Rubens Barbosa; GOUVEIA, Andréa Barbosa; CRUZ, Rosana Evangelista da; OLIVEIRA, João Ferreira de. Condições de trabalho docente, ensino de qualidade e custoaluno-ano. Revista Brasileira de Política e Administração da Educação, Goiânia, v. 22, p. 253-276, 2006.

CNTE. Tabela de Vencimentos. Confederação Nacional dos Trabalhadores em Educação. Brasília, 2016.

DOURADO, Luiz Fernandes. Diretrizes curriculares nacionais para a formação inicial e continuada dos profissionais do magistério da educação básica: concepções e desafios. Educação e sociedade, Campinas, v. 36, p. 299-324, 2015.

DOURADO, Luiz Fernandes. Valorização dos profissionais da educação Desafios para garantir conquistas da democracia. Retratos da Escola, Brasília, v. 10, p. 37-56, 2016.

FÓRUM NACIONAL DE EDUCAÇÃO. Conae 2018: Conferência Nacional de Educação: documento - referência. Fórum Nacional de Educação. Brasília, 2017.

FRIGOTTO, Gaudêncio; CIAVATTA, Maria. Perspectivas sociais e políticas da formação de nível Médio: avanços e entraves nas suas modalidades. Educação e Sociedade, Campinas, v. 32, n. 116, p. 619-638, jul./set./2011.

FRIGOTTO, Gaudêncio. Reforma do ensino médio do (des) governo de turno: decreta-se uma escola para os ricos e outra para os pobres. Movimento Revista de Educação, Rio de Janeiro, ano 3, n. 5, 2016.

GOUVEIA, Andréa Barbosa. (Org.); PINTO, José Marcelino de Rezende (Org.); CORBUCCI, Paulo Roberto (Org.). Federalismo e políticas educacionais na efetivação do direito à educação. Brasília: IPEA, 2011. v. 1. 227 p. 
IBGE. Pesquisa Nacional por Amostra de Domicílios (PNAD): 1991-2018. Brasília, 2018.

KRAWCZYK, Nora; FERRETTI, Celso João. Flexibilizar para quê? Meias verdades da "reforma". Revista Retratos da Escola, Brasília, v. 11, n. 20, p. 33-44, jan./jun. 2017.

KUENZER, Acácia Zeneida. O Ensino Médio no plano nacional de educação 2011-2020: superando a década perdida? Educação e Sociedade, Campinas, v. 31, n. 112, p. 851-873, julho-setembro/2010.

KUENZER, Acácia Zeneida. A formação de professores para o Ensino Médio: velhos problemas, novos desafios. Educação e Sociedade. Campinas, v. 32, n. 116, p. 667-688, julho-setembro, 2011.

LIMA, Marcelo; MACIEL, Samanta Lopes. A reforma do Ensino Médio do governo Temer: corrosão do direito à educação no contexto de crise do capital no Brasil. Revista Brasileira de Educação, Rio de Janeiro, v. 23, p. 01-25, 2018.

MASSON, Gisele. A valorização dos professores e a educação básica nos estados.

Retratos da Escola, Brasília, v. 10, p. 157-174, 2016.

MORAES, Carmen Sylvia Vidigal. O ensino médio e as comparações internacionais: Brasil, Inglaterra e Finlândia. Educação e Sociedade, Campinas, v. 38, nº. 139, p.405-429, abr./set., 2017.

MOURA, Dante Henrique; LIMA FILHO, Domingos Leite. A reforma do ensino médio: regressão de direitos sociais. Revista Retratos da Escola, Brasília, v. 11, n. 20, p. 109129, jan./jun, 2017.

NOSELLA, P. Ensino Médio: em busca do princípio pedagógico. Educação e Sociedade, Campinas, v.32, n.117, p.1051-1066, outubro-dezembro/2011.

NOSELLA, P.; BUFFA, E. As pesquisas sobre Instituições Escolares: o método dialético marxista de investigação. Eccos. Revista Científica, São Paulo, v. 7, n. 2, p. 351-368, julhodezembro, 2005.

OLIVEIRA, Dalila Andrade. Regulação Educativa na América Latina: repercussões sobre a identidade dos trabalhadores docentes. Educação em Revista, Belo Horizonte, v. 44, p. 209$227,2006$.

OLIVEIRA, Dalila Andrade. O Ensino Médio perante a obrigatoriedade ampliada: que lições podemos tirar de experiências observadas? Revista Brasileira de Estudos Pedagógicos, Brasília, v. 91, p. 10-26, 2010.

OLIVEIRA, Dalila Andrade. Os docentes no Plano Nacional de Educação: entre a valorização e a desprofissionalização. Retratos da Escola, Brasília, v. 8, n. 15, p. 447-461, jul./dez. 2014.

OLIVEIRA, Dalila Andrade; ASSUNÇÃO, Ada Avila . Condições de trabalho docente.

Belo Horizonte: GESTRADO/FAE/UFMG, 2010 (Verbete). 
PINTO, Mércia Noronha; DUARTE, Adriana; VIEIRA, Livia Maria Fraga. O trabalho docente na educação infantil pública de Belo Horizonte. Revista Brasileira de Educação, v. 17, p. 611-626, 2012.

SAVIANI, Dermeval. Vicissitudes e perspectivas do direito à educação no Brasil: abordagem histórica e situação atual. Educação e Sociedade, Campinas, v. 34, n. 124, p. 743-760, jul./set. 2013.

SAVIANI, Dermeval. Formação de professores no Brasil: dilemas e perspectivas. Poíesis Pedagógica. v.9, n.1 jan/jun, 2011.

SILVA, Monica Ribeiro da. Direito à educação, universalização e qualidade: cenários da Educação Básica e da particularidade do Ensino Médio. Jornal de Políticas Educacionais, v. 9, p. 61-74, 2015.

SILVA, Monica Ribeiro da. O Ensino Médio reformado: perguntas e respostas, tensões e proposições. In: Glauco Vaz Feijó e Thiago de Faria e Silva (Org.). Ensino e pesquisa em história e humanidades nos institutos federais de educação, ciência e tecnologia: desafios e perspectivas. Brasília: Ed. IFB, 2017. p. 16-29.

SILVA, Monica Ribeiro da; SCHEIBE, Leda. Reforma do ensino médio: Pragmatismo e lógica mercantil. Revista Retratos da Escola, Brasília, v. 11, n. 20, p. 19-31, jan./jun. 2017.

\section{SOBRE O AUTOR:}

\section{Gilvan Luiz Machado Costa}

Doutor em Educação pela Universidade Estadual de Campinas (UNICAMP). Professor do Programa de Pós-Graduação em Educação da Universidade do Sul de Santa Catarina (UNISUL). Pesquisador no Grupo Política e Gestão da Educação. E-mail: gilvan.costa@unisul.br

(iD) http://orcid.org/0000-0002-1825-0097 